
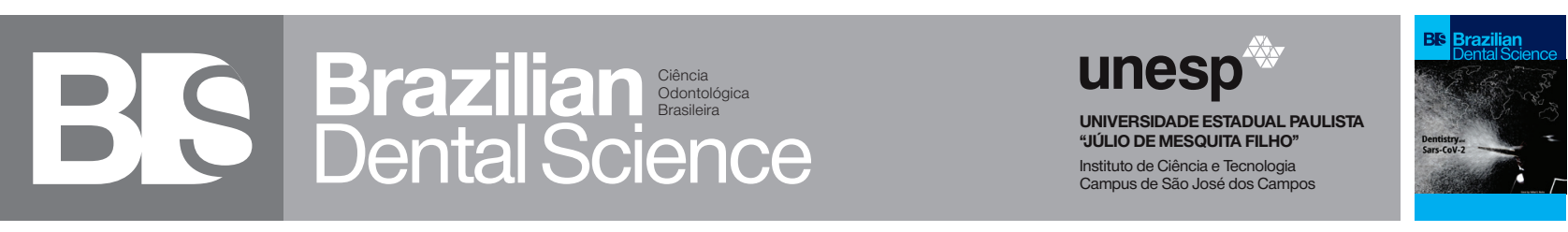

\title{
COVID-19 and Geriatric Dentistry: What will be the new-normal?
}

COVID-19 e Odontologia Geriátrica: Qual será o novo normal?

Leonardo MARCHINI ${ }^{1}$, Ronald L. ETTINGER ${ }^{2}$

1 - Department of Preventive and Community Dentistry - University of Iowa College of Dentistry and Dental Clinics - Iowa City - Iowa.

2 - Department of Prosthodontics - University of Iowa College of Dentistry and Dental Clinics - Iowa City - Iowa.

\section{ABSTRACT}

Older adults may face many barriers when accessing oral health care. The most vulnerable groups are people living in long term care institutions and the homebound. These barriers are related but not limited to socio-economic issues, medical and oral health problems. Some socio-economic problems are lack of finances, absence of dental insurance, lack of social support networks, and being institutionalized. Some general health problems are multiple co-morbidities, polypharmacy, dementia, and reduced autonomy. Some oral health problems are having heavily restored dentitions, dry mouth, root caries, and inability to maintain adequate oral hygiene independently. In addition to these existing barriers, many new barriers have arisen which are expected to further reduce access to oral health care for older adults due to the emergence of the COVID-19 pandemic. Older adults are at greater risk of fatal outcomes from COVID-19 infection and many dental procedures have an increased risk of creating aerosols, thereby spreading COVID-19 infection. Consequently, older adults due to fear are less likely to seek or receive oral health care until a treatment or vaccine is developed for COVID-19 infections. In this article, the authors discuss the implications of the COVID-19 pandemic to the practice of geriatric dentistry, and what is expected to be the "new normal" in this field of dentistry.

\section{KEYWORDS}

Aged; COVID-19; Geriatric Dentistry; Older Adults; Oral Health; SARS-CoV-2.

\section{RESUMO}

Os idosos geralmente enfrentam muitas barreiras para acessar os serviços de saúde bucal. Os grupos mais vulneráveis são formados por pessoas que vivem em instituições de longa permanência ou estão restritos às suas casas. Essas barreiras estão relacionadas, entre outras, a questões socioeconômicas e problemas de saúde geral e oral. Alguns problemas socioeconômicos são: problemas financeiros, falta de convênio odontológico, falta de redes de apoio social e institucionalização. Alguns problemas gerais de saúde são: múltiplas comorbidades, polifarmácia, demência e autonomia reduzida. Alguns problemas de saúde bucal são: dentição muito restaurada, boca seca, cárie radicular e incapacidade de manter uma higiene bucal adequada de forma independente. Além das barreiras já existentes, devido ao surgimento da pandemia de COVID-19 surgiram novas barreiras que deverão reduzir ainda mais o acesso aos cuidados de saúde bucal para idosos. Idosos correm maior risco de complicações fatais da COVID-19 e muitos procedimentos odontológicos têm um risco aumentado de gerar aerossóis, espalhando assim a COVID-19. Consequentemente, os idosos têm menor probabilidade de procurar ou receber cuidados de saúde bucal devido ao medo, até que um tratamento ou vacina seja desenvolvido para a COVID-19. Neste artigo, os autores discutem as implicações da pandemia de COVID-19 na prática da odontologia geriátrica e o que se espera ser o "novo normal" nesse campo da Odontologia.

\section{PALAVRAS-CHAVE}

Idosos; COVID-19; Odontologia Geriátrica; Envelhecimento; Saúde Bucal; SARS-CoV-2. 


\section{INTRODUCTION}

$\mathrm{T}$ he world population is aging [1], and more older adults are keeping their teeth as they age [2]. Therefore, there is an increasing need to provide age appropriate oral health care for this growing population of older adults [3].

A significant proportion of the older adults population [geriatric] - about 70\% - live independently in the community and can access oral health care similarly to young adults [4]. This group of older adults is called functionally independent [4], and often are prescribed medications to control their common age-related co-morbidities, such as diabetes, hypertension, osteo-arthritis and osteoporosis. Functionally independent older adults have the ability to drive and/or to use public transport themselves in order to access oral health care services. General dentists are able to safely treat these persons, provided the dentists have the necessary knowledge about physiology, medicine and pharmacology related to the patients common chronic diseases and how they impact dental care [4].

However, there is another group of older adults that requires the oral health care provider to have more advanced skills and knowledge [4]. This group includes persons that can still access oral health care in the community, provided somebody provides transport. Persons in this group are called frail older adults, and comprise about 20\% of the older adult population [4]. These persons have more complex medical histories and pharmacotherapies, which may require consultation with their physician prior to invasive treatment. Another group consist of older adults who are homebound or living in institutions. The best way to provide oral health care for these persons may be to treat them in their own environment. These persons are called functionally dependent older adults, and encompass about $10 \%$ of persons over the age of 65 years [4].

Frail and functionally dependent older adults face many barriers in trying to access oral health care. These barriers can be grouped as socio-economic, general health and oral health problems [5]. Socio-economic barriers include but are not limited to ageism [6], financial constraints [7], lack of dental insurance [8], lack of social support [7], and being institutionalized [9]. General healthrelated barriers are due to the increased complexity of care caused by the presence of multiple co-morbidities [10], polypharmacy [11], cognitive impairments, such as dementia [12], reduced mobility [8], and impaired manual dexterity [13]. Oral health issues that make dental care more challenging for these persons include xerostomia [11], root caries [14], heavily restored dentitions [14] and inability to maintain oral hygiene independently [14].

With the emergence of severe acute respiratory syndrome coronavirus 2 - SARSCoV-2 - that causes 2019 coronavirus disease - COVID-19 [15], new challenges to accessing oral health care have arisen for frail functionally dependent older adults [16]. The problem is caused by the synergistic effect of two factors: 1] older age and the presence of co-morbidities, which have been clearly linked to fatal outcomes of COVID-19 infection $[17,18]$; also 2] many dental procedures produce aerosols, which is the way that SARSCoV-2 infection is transmitted [19].

Consequently, until an effective treatment or vaccine is developed for COVID-19 infection, it is unrealistic to expect that frail and functionally dependent older adults and their caregivers/guardians will expose themselves to dental procedures. In the new normal, dentistry will need to adhere to new oral health care workflow protocols, which will include pre-screenings, social distancing, and new infection control procedures intended to prevent respiratory pathogens spread $[19,20]$. These new procedures will pose new barriers for frail and functionally dependent older adults, since these patients will include many persons with cognitive impairments, such as 
dementia, complicating social distancing and the new enhanced infection control protocols.

In this article, the authors discuss the implications of the COVID-19 pandemic to the practice of geriatric dentistry, and what is expected to be the "new normal" in this field of dentistry.

\section{COVID-19 AND OLDER ADULTS}

Older adults have a less efficient immune system and therefore are more susceptible to emerging infectious diseases [21,22]. Consequently, it is not surprising that data have shown that older adults were more at risk for COVID-19 infection [22]. In addition, older adults who have co-morbidities are at an increased risk of fatal outcomes from COVID-19 infection [18,23].

The clinical presentation of COVID-19 among older adults includes some of the same symptoms which have been described for the general population, such as shortness of breath, fever and cough [24]. However, older adults can have atypical clinical presentations, including non-specific symptoms, such as a vague dizziness, delirium, functional decline and falls [25]. The existence of multiple morbidities with similar symptoms may mask COVID-19 symptoms, and cognitive and/or sensory impairment might limit the ability of frail and functionally dependent older adults to correctly report their symptoms [25]. Appropriately identifying problems is especially challenging for older persons with dementia [22]. Therefore, the current COVID-19 screening protocols, based on typical symptoms alone, seem insufficient to correctly diagnose COVID-19 infection [25]. The availability of effective rapid testing may solve some of these problems.

As stated earlier, older adults frequently present with multiple comorbidities, such as hypertension, diabetes, chronic kidney disease, cardiovascular disease and chronic respiratory diseases [10,24]. Many older adults have been prescribed angiotensin receptor blockers [ARB] and angiotensin converter enzyme - ACE - inhibitors to treat some of these chronic illnesses. Both ARB and ACE inhibitors upregulate ACE 2 receptors, which are the receptors used by SARSCoV-2 to enter host cells. Therefore, patients prescribed with these medications are at even higher risk of SARS-CoV-2 infection [24]. In addition, some older patients who survived COVID-19 infections will present with organ damage caused by the disease, such as acute respiratory distress syndrome, acute kidney injury, and cardiac injury [24].

Older adults living in long term care facilities - LTCF's - are at an even higher risk of COVID-19 infection due to their multiple health conditions and the impact of living in a group home [22]. Other risk factors for these residents are related to the staff caring for them. Many caregivers are undereducated and/or poorly trained, live in multi-generation homes and cannot practice social distancing, especially when using public transport. This increases their risk of getting infected and bringing the virus to LTCF's. Therefore, LTCF's have become hot spots for COVID-19 spread, and outbreaks in LTCF's have a significant impact on the health and well-being of the residents and staff, resulting in a high number of fatalities [26]. In addition, not only are residents of LTCF's at a higher risk of mortality, but they may present with atypical symptoms, making the diagnosis of COVID-19 infection even more challenging [27]. With the current shortage of tests and personal protective equipment - PPE, many outbreaks of COVID-19 in LTCF's have occurred [27]. In order to avoid these outbreaks, LTCF's need to take proactive preventive steps, including but not limited to banning visitors, identifying and quarantining infected staff members, providing single rooms for residents, and implementing effective infection control procedures. Other preventive procedures may be to avoid group activities, and establish appropriate protocols for sending patients to and receiving patients from hospitals [26,27]. 
Older persons living in LTCFs have become a center of the COVID-19 crisis, but community-dwelling older adults, including those who are frail, have received less attention [28]. This lack of focus can have severe consequences for the well-being of frail older persons living in the community. The effects of required confinement increases their difficulty in accessing needed services and may cause negative mental health effects due to isolation and reduced access to nutritious meals due to social distancing and inability to shop for food. There is an increased challenge for frail older adults to establish communication with others due to social distancing and wearing of masks due to their poor eye sight and inability to lip read [29].

Older adults with co-morbidities have a high prevalence of morbidity and mortality due to the COVID-19 pandemic [22], which often has isolated them from their families [30]. There is discussion in the literature questioning if older adults will benefit from COVID-19 vaccines $[21,22]$, because they have a less effective and less coordinated immune system [21]. It seems that their responses to SARS-CoV-2 do not functionally transition from innate to adaptive immunity, resulting in little or no antibody production [22]. Consequently, for a vaccine to be effective among older adults it needs to incorporate age-appropriate adjuvants to stimulate appropriate antibody responses among older persons [22].

Currently, the best way to avoid the negative consequences of COVID-19 amongst older adults are still preventive measures, such as isolation, social distancing and enhanced infection control protocols. However, some of the undesirable side effects of these preventive measures include but are not limited to nutritional challenges, reduction in physical activity, increased stress levels, and restricted access to health care $[29,31]$. Elective health problems after delayed treatment may become urgent problems. Therefore, unintended consequences might precipitate a higher demand for health care services including dentistry when the current crisis is reduced [31].

\section{COVID-19 AND GERIATRIC DENTISTRY}

During the COVID-19 pandemic, elective dental procedures have been suspended in most countries. Only emergency care has been provided in many dental practices to avoid patients overwhelming the already overflowing emergency rooms in hospitals [32]. Many dental practices are using teletriage to interview patients and determine their needs $[33,34]$. Most LTCF's have not integrated oral health care into their protocols, and due to the policy of reducing visitors [27], oral health care delivery has been virtually halted in most LTCF's during this pandemic.

Historically, most oral health care for older adults has been related to chronic oral health problems, rather than acute exacerbations, which are not very prevalent among this age group [35]. Therefore, older adults are less likely to suffer from acute dental problems during the current COVID-19 pandemic. However, chronic dental problems are likely to get worse during the crisis, because caregivers are focused on preventing of COVID-19, so that oral hygiene routines for residents may be further neglected, resulting in acute needs [36,37].

Nevertheless, when elective procedures in dental care around the world are resumed, it is possible that frail and functionally dependent older adults will face even greater barriers in trying to access oral health care. Being the most high risk group for fatal outcomes for COVID-19 infection [17,18], frail and functionally dependent patients and their guardians are more likely to defer any elective dental procedures due to the fear of SARS-CoV-2 infection. Dentists are also likely to recommend their older adults patients to avoid elective treatment until they solve the problem of aerosol control in their practices. 
For patients with urgent or progressing dental problems, new challenges will begin with obtaining appropriate consents from patients, guardians and caregivers during the recommended tele-triage pre-operatory procedures [20]. Currently, this is timeconsuming and not billable. Tele triage itself is challenging for this population, not only due to the persistent digital divide among different generations [29], but also because many frail and functionally dependent older adults have sensory and/or cognitive impairments and will find it difficult to appropriately communicate through a telephone or video call [16].

In addition, existing protocols for teletriage, which are being developed target a more tech savvy population, and need to be adapted for frail and functionally dependent older adults. For instance, one of the teletriage questions is related to level of pain, which requires the patient to respond by using a scale from 0 to 10 [20]. Older adults tend to report less pain and have a higher tolerance to pain [38], therefore the thresholds for triggering a dental visit using tele-triage needs to be adjusted accordingly. Older adults with mild to moderate dementia are often unable to report the quality of their pain [12,39], and triage procedure need to be adapted for this group by including questions about nonverbal signs of pain and feedback from their caretakers [12, 39].

The next step after tele-triage is to make an appointment with the dental office. The new norms for infection control [20] are also expected to be especially challenging for this group of patients. In the waiting room, the need to maintain social distance, cough and sneeze etiquette, and wearing masks may be from difficult or virtually impossible for older persons with dementia. This may result in an increasing demand for those patients to be treated in their own environments, which has proved to be difficult and not cost effective for many dentists [40]. In addition, if the person with dementia is living in a LTCF, it is likely that the facility may have a restrictions for visiting by health care providers that are not part of the usual team $[26,27]$.

The newly recommended PPE for treating patients includes facial shields, N-95 or similar respirators, and eye protection goggles [19,20,34], which might frighten older persons with dementia and also make it much more difficult to communicate with patients with sensory impairments, as they cannot lip read [16]. Current restrictions in limiting escorts in the dental operatory $[19,20,34]$ will need to be lifted to allow caregivers to be present, however they will need appropriate PPE, which increases cost.

Currently, aerosol generating procedures should be avoided [19, 20, 34] in open areas. Contemporary conservative approaches for treating caries among frail and functionally dependent older adults, like the use of silverdiamine fluoride - SDF - and atraumatic restorative techniques - ART, such as using hand instruments and glass-ionomer cements [14], are likely to become more routine.

\section{CONCLUSION}

In summary, providing oral health care for frail and functionally dependent older adults is facing important new challenges due to the emergence of COVID-19 infection, and will continue to include new barriers at least until an effective treatment/vaccine is developed.

For homebound and dependent older adults, in order to avoid predictable increases in oral hygiene problems during this crisis it is important to establish good communications with caregivers in LTCF's. Using empathetic listening and compassionate care, the dentist/ hygienist should be able to encourage oral hygiene routines to be maintained, in spite of the current stresses over the pandemic. Teledentistry can be an important ally to encourage the maintenance of oral hygiene routines and the ability to evaluate urgent oral health problems. 
When dentists can resume delivery of elective procedures, communication will be the key for ensuring a smooth transition to the "new normal". When determining if a frail and functionally dependent older adult needs to have a face-to-face appointment, the clinician will need to decide where the patient should be seen, and what should the patient and his/ her caregiver expect during the appointment. This needs to be carefully considered and explained to the patients and his/her caregiver before setting up the appointment.

\section{REFERENCES}

1. WWolrd Health Organization. World report on ageing and health. WHO;2015. p. 260

2. Dye BA, Weatherspoon DJ, Lopez Mitnik G. Tooth loss among older adults according to poverty status in the United States from 1999 through 2004 and 2009 through 2014. J Am Dent Assoc. 2019;150(1):9-23.e3. doi:10.1016/j. adaj.2018.09.010

3. Marchini L, Ettinger R, Chen X, Kossioni A, Tan H, Tada S, etal. Geriatric dentistry education and context in a selection of countries in 5 continents. Spec Care Dentist. 2018;38(3):123-32. doi:10.1111/scd.12281

4. Ettinger RL, Beck JD. The new elderly: what can the dental profession expect?. Spec Care Dentist 1982;2(2):62-9. doi:10.1111/:.1754-4505.1982.tb01282.x

5. Marchini L, Hartshorn JE, Cowen H, Dawson DV, Johnsen DC. A Teaching tool for establishing risk of oral health deterioration in elderly patients: development, implementation, and evaluation at a U.S. Dental School. J Dent Educ. 2017;81(11):1283-90. doi:10.21815/JDE.017.086

6. Wyman MF,Shiovitz-EzraS, Bengel J. Ageism in the health care system: providers, patients, and systems. in: ayalon l, tesch-römer c, editors. contemporary perspectives on ageism. Cham: Springer International Publishing;2018. p. 193-212.

7. Friedman PK, Kaufman LB, Karpas SL Oral health disparity in older adults: dental decay and tooth loss. Dent Clin North Am. 2014;58(4):757-70. doi:10.1016/j.cden.2014.06.004

8. Marchini L, Reynolds JC, Caplan DJ, Sasser S, Russell C. Predictors of having a dentist among older adults in lowa. Community Dent Oral Epidemiol. 2020;48(3):240-7. doi:10.1111//cdoe.12521

9. Kelly MC, Caplan DJ, Bern-Klug M, Cowen HJ, Cunningham-Ford MA, Marchin $\mathrm{L}$, et al. Preventive dental care among Medicaid-enrolled senior adults: from community to nursing facility residence. J Public Health Dent. 2018;78(1):86-92. doi:10.1111/jphd.12247

10. de Deco CP,do Santos JF, da Cunha Vde P,Marchini L. General health of elderly institutionalised and community-dwelling Brazilians. Gerodontology. 2007;24(3):136-42. doi:10.1111/.1741-2358.2007.00174.x

11. Barbe AG. Medication-induced xerostomia and hyposalivation in the elderly: culprits, complications, and management. Drugs Aging. 2018;35(10):877-85. doi:10.1007/s40266-018-0588-5

12. Marchini L, Ettinger R, Caprio T,Jucan A. Oral health care for patients with Alzheimer's disease: An update. Spec Care Dentist. 2019;39(3):262-73. doi:10.1111/scd.12375
13. Marchini L, Vieira PC, Bossan TP,Montenegro FL,Cunha VP.Self-reported oral hygiene habits among institutionalised elderly and their relationship to the condition of oral tissues in Taubaté, Brazil. Gerodontology.2006;23(1):33-7. doi:10.1111/.1741-2358.2006.00092.x

14. Marchini L, Ettinger R, Hartshorn J. Personalized dental caries management for frail older adults and persons with special needs. Dent Clin North Am. 2019;63(4):631-51. doi:10.1016/.j.cden.2019.06.003

15. Del Rio C,Malani PN. COVID-19-New insights on a rapidly changing epidemic. JAMA. 2020;10.1001/jama.2020.3072. doi:10.1001/jama.2020.3072

16. Marchini L, Ettinger RL. COVID-19 pandemics and oral health care for older adults. Spec Care Dentist. 2020;40(3):329-31. doi:10.1111/scd.12465

17. Chen N, Zhou M, Dong X, et al. Epidemiological and clinical characteristics of 99 cases of 2019 novel coronavirus pneumonia in Wuhan, China: a descriptive study. Lancet. 2020;395(10223):507-13. doi:10.1016/S0140-6736(20)30211-7

18. Weiss P,Murdoch DR. Clinical course and mortality risk of severe COVID-19. Lancet. 2020;395(10229):1014-5. doi:10.1016/S0140-6736(20)30633-4

19. Meng L, Hua F, Bian Z Coronavirus Disease 2019 (COVID-19): Emerging and future challenges for dental and oral medicine. J Dent Res. 2020;99(5):481-7. doi:10.1177/0022034520914246

20. American Dental Association. ADA Interim Guidance for Minimizing Risk of COVID-19 Transmission 2020 [Internet]. Available from: https://www.ada. org/ /media/CPS/Files/COVID/ADA_COVID_Int_Guidance_Treat_Pts.pdf.

21. Pawelec G, Weng NP.Can an effective SARS-CoV-2 vaccine be developed for the older population? Immun Ageing. 2020;17:8. Published 2020 Apr 11. doi:10.1186/s12979-020-00180-2

22. Nikolich-Zugich J, Knox KS, Rios CT,NattB, Bhattacharya D, Fain MJ. SARS-CoV-2 and COVID-19 in older adults: what we may expect regarding pathogenesis, immune responses, and outcomes. Geroscience. 2020;42(2):505-14. doi:10.1007/s11357-020-00186-0

23. Zhou F, Yu T,DuR, Fan G, Liu Y, LiuZ, etal. Clinical course and risk factors for mortality of adult inpatients with COVID-19 in Wuhan, China: a retrospective cohort study [published correction appears in Lancet.2020 Mar 28;395(10229):1038] [published correction appears in Lancet.2020 Mar 28;395(10229):1038]. Lancet. 2020;395(10229):1054-1062. doi:10.1016/S01406736(20)30566-3

24. ShahidZ, Kalayanamitra R, McClafferty B, Kepko D, Ramgobin D, Patel R, etal. COVID-19 and Older Adults: What We Know. J Am Geriatr Soc. 2020;68(5):9269. doi:10.1111/jgs.16472

25. Norman RE, Stall NM, Sinha SK. Typically Atypical: COVID-19 Presenting asa Fall in an Older Adult. J Am Geriatr Soc. 2020. Norman RE, Stall NM, Sinha SK Typically atypical:COVID-19 presenting as a fall in an older adult [published online ahead of print, 2020 Apr 28]. J Am Geriatr Soc. 2020;10.111//jgs.16526. doi:10.1111/jgs.16526

26. McMichael TM, Clark S, Pogosjans S, Kay M, Lewis J, Baer A, etal. COVID-19 in a long-term care facility - King County, Washington, February 27-March 9 , 2020. MMWR Morb Mortal Wkly Rep. 2020;69(12):339-42. Published 2020 Mar 27. doi:10.15585/mmwrmm6912e-1

27. American Geriatrics Society. American Geriatrics Society Policy Brief: COVID-19 and Nursing Homes. J Am Geriatr Soc. 2020;68(5):908-11. doi:10.1111/ jgs.16477

28. Lloyd-Sherlock PG, Kalache A,McKee M, Derbyshire J, Geffen L, Casas FG. WHO must prioritise the needs of older people in its response to the covid-19 pandemic [published correction appears in BMJ. 2020 Mar 31;368:m1285]. BMJ. 2020;368:m1164. Published 2020 Mar 23. doi:10.1136/bmj.m1164

29. Petretto DR, Pili R. Ageing and COVID-19: what is the role for elderly people? Geriatrics (Basel). 2020;5(2):E25. doi:10.3390/geriatrics5020025 
30. Sinvani L. The COVID-19Pandemic: experiences of a geriatrician-hospitalist caring for older adults. J Am Geriatr Soc. 2020;68(5):934-5. doi:10.1111/jgs.1648

31. Schrack JA, Wanigatunga AA, Juraschek SP. After the COVID-19 pandemic: the next wave of health challenges for older adults [published online ahead of print, 2020 Apr 21].J Gerontol A Biol Sci Med Sci.2020;glaa102. doi:10.1093/ gerona/glaa102

32. Dave M, Seoudi N,Coulthard P.Urgent dental care for patients during the COVID-19 pandemic. Lancet. 2020;395(10232):1257. doi:101016/S01406736(20)30806-0

33. Yang Y,Zhou Y,LiuX, Tan J. Health services provision of 48 public tertiary dental hospitals during the COVID-19 epidemic in China. Clin Oral Investig. 2020;24(5):1861-4. doi:10.1007/s00784-020-03267-8

34. Ren YF, Rasubala L, Malmstrom H, EliavE. Dental care and oral health under the clouds of COVID-19 [published online ahead of print,2020 Apr 24].JDR Clin Trans Res. 2020;2380084420924385. doi:10.1177/2380084420924385

35. Delwel S, Binnekade TT,Perez RS, Hertogh CM, Scherder EJ, Lobbezoo F. Oral health and orofacial pain in older people with dementia: a systematic review with focus on dental hard tissues. Clin Oral Investig.2017;21(1):17-32. doi:10.1007/s00784-016-1934-9
36. De Visschere LM, Grooten L, Theuniers G, Vanobbergen JN. Oral hygien of elderly people in long-term care institutions--a cross-sectional study. Gerodontology.2006;23(4):195204. doi:10.1111/j.1741-2358.2006.00139.x

37. Marchini L, Recker E, Hartshorn J, et al. lowa nursing facility oral hygiene (INFOH) intervention: aclinical and microbiological pilot randomized trial. Spec Care Dentist. 2018;38(6):345-55. doi:10.1111/scd.12327

38. Lautenbacher S, Peters JH, Heesen M, Scheel J, Kunz M. Age changes in pain perception: a systematic-review and meta-analysis of age effects on pain and tolerance thresholds. Neurosci Biobehav Rev. 2017;75:104-13. doi:10.1016/j. neubiorev.2017.01.039

39. Lobbezoo F,Delwel S, Weijenberg RAF, Scherder EJA. Orofacial pain and mastication in dementia. Curr Alzheimer Res. 2017;14(5):506-11. doi:10.2174/156 7205013666160602233535

40. Cunha Jr AP, dos Santos MBF, Santos JFF, Marchini L. Dentists' perceptions and barriers to provide oral care for dependent elderly athome, long-term care institutions or hospitals. Braz J Oral Sci. 2018:17;e18223. doi:10.20396/bjos. v17i0.8654155

\section{Dr. Leonardo Marchini \\ (Corresponding address)}

N337-1 Dental Science

Iowa City, Iowa - 52242

Date submitted: 2020 May 22

E-mail: leonardo-marchini@uiowa.edu 